\title{
USO DA FISIOTERAPIA NO PÓS-OPERATÓRIO DE EXCISÃO ARTROPLÁSTICA DA CABEÇA E COLO FEMORAL EM UM CANINO - RELATO DE CASO
}

(Use of physiotherapy in the artroplastic excision post-operative of the head and femoral lap in a canine Case report)

Eduardo Lux, Marina Soethe, Giovanna Costa Grotti, Talita Caballero Wang, Anna Carolina Montichel, Bruna Marcelino, Kelly Mota Fernandes, Fabiano Zanini Salbego

Universidade do Estado de Santa Catarina - Centro de Ciências Agroveterinárias, Brasil

*Correspondência: medvet.elux@gmail.com

Resumo: A excisão artroplástica da cabeça e colo femoral é um procedimento corretivo da articulação coxofemoral que visa a formação de uma pseudoartrose, porém o seu pósoperatório pode cursar com diversas complicações (OFF; MATIS, 2010). Assim, o presente relato objetivou discorrer a respeito do emprego da fisioterapia no tratamento das complicações decorrentes do pós-operatório desse procedimento cirúrgico. Foi encaminhado ao setor de fisioterapia do hospital veterinário da UDESC, um canino, macho, Bull Terrier e com dois anos de idade, apresentando histórico de trauma e claudicação em membro pélvico direito. Ao exame ortopédico, observou-se elevação do trocanter maior e rotação externa do membro pélvico direito, indicando um quadro de luxação coxofemoral, o qual foi confirmado ao exame radiográfico, estando associado a uma fratura no colo femoral. O animal foi encaminhado ao procedimento cirúrgico, sendo optado pela excisão artroplástica da cabeça e colo femoral direito. Após três semanas de pós-operatório, observou-se claudicação, com ausência de apoio do membro pélvico direito ao solo e presença de atrofia muscular significativa com grau moderado de contratura do quadríceps femoral. O tratamento fisioterapêutico constituiu-se de massagem na modalidade effleurage sobre a região médio-proximal do quadríceps femoral direito, por fricção direta com pressão moderada, durante 5 min ininterruptos. O ultrassom terapêutico foi empregado no modo pulsado, dosimetria de $0,5 \mathrm{~W} / \mathrm{cm}^{2}$, sendo aplicado sobre o músculo glúteo superficial por $5 \mathrm{~min}$. A eletroterapia foi realizada com quatro eletrodos aplicados em orientação bipolar sobre os músculos quadríceps e bíceps femoral, utilizando-se corrente FES, frequência de $50 \mathrm{~Hz}$, pulso de $200 \mu \mathrm{s}$ e ciclos de $12 \mathrm{~s}$ seguidos por $36 \mathrm{~s}$ de descanso (relação on:off 1:3), durante $10 \mathrm{~min}$. A hidroterapia por turbilhonamento foi realizada com imersão parcial do membro até o nível do trocanter maior do fêmur a $40{ }^{\circ} \mathrm{C}$ por $15 \mathrm{~min}$. $\mathrm{O}$ protocolo era finalizado com caminhada controlada na guia durante 20 min, com alternância da superfície de apoio e do ângulo de inclinação da pista. O protocolo instituiu-se por dez sessões, com intervalos de 48 horas entre cada sessão. Em relação à evolução, o apoio do membro ao solo iniciou a ser observado a partir da $3^{a}$ sessão, sendo que ao término da $10^{a}$ sessão, o animal apresentava apoio contínuo do membro, com descarga adequada do peso corporal. Com a resposta positiva ao tratamento, as caminhadas controladas passaram a ser realizadas pelos tutores. Considera-se que a massagem terapêutica tenha estimulado os receptores periféricos, provendo relaxamento e mobilização muscular, e melhora no retorno venoso e linfático. Atribuiu-se ao ultrassom, a melhora do quadro álgico, a diminuição da rigidez articular, o aumento do fluxo sanguíneo e a redução dos espasmos musculares, enquanto a cinesioterapia, a eletroterapia e a hidroterapia auxiliaram no fortalecimento muscular, reeducação do movimento e melhora da circulação sanguínea (VICENTE; HUMMEL, 2019). Sendo assim, pode-se concluir que o protocolo fisioterapêutico empregado se demonstrou eficaz e seguro para o restabelecimento do uso funcional do membro acometido, resultando em ganho de massa muscular, maior amplitude de movimento articular e melhora no apoio do membro ao solo.

Palavras-chave: cinesioterapia; eletroterapia; hidroterapia; massagem; ultrassom. 


\section{Referências}

OFF, W.; MATIS, U. Excision arthroplasty of the hip joint in dogs and cats: clinical, radiographic, and gait analysis findings from the Department of Surgery, Veterinary Faculty of the LudwigMaximilians-University of Munich, Germany. Veterinary and Comparative Orthopaedics and Traumatology, v. 23, n. 5, p. 297-305, 2010.

VICENTE, G.; HUMMEL, J. Tratado de fisioterapia e fisiatria em pequenos animais. São Paulo: Paya, 2019. 